\title{
Speleothem records over the last interglacial
}

Dominique Genty ${ }^{1}$, S. Verheyden² and K. Wainer ${ }^{3}$

'Laboratoire des Sciences du Climat et de l'Environnement, CEA Saclay, Gif-sur-Yvette, France; dominique.genty@lsce.ipsl.fr ${ }^{2}$ Geological Survey, Royal Belgian Institute of Natural Sciences, Belgium; ${ }^{3}$ Department of Earth Sciences, University of Oxford, UK

We present a review of 13 speleothems from Europe, Asia and South America, covering the penultimate deglaciation and the last interglacial. We highlight the similarities and regional differences in the growth rate and the calcite $\delta^{18} \mathrm{O}$ records in these cave deposits.

$T^{\mathrm{h}} \mathrm{d}$ he discovery of speleothems (cave calcite deposits) as paleoenvironmental archives has significantly enriched the toolbox for reconstructing past changes over the continents. Indeed, research over the last decade has demonstrated the potential of speleothems for providing unique paleoenvironmental and paleoclimatic information based on: (1) precise chronologies relying on Uranium-series dating and (2) high-resolution continental climate records based on carbon and oxygen isotope $\left(\delta^{13} \mathrm{C}\right.$ and $\delta^{18} \mathrm{O}$ respectively) measurements of the calcite.

Among other results, speleothems have revealed that the Asian and South American monsoons show an anti-phase pattern (Cruz et al. 2005; Cruz et al. 2006a) paced by Earth's precession changes (Wang et al. 2001; Wang et al. 2008). In the Northern Hemisphere temperate zone, the millennial scale climatic Dansgaard-Oeschger events occurring frequently over Marine Isotopic Stage 3 (28-60 ka BP) have been detected in stalagmites from Turkey (Fleitmann et al. 2009), from the Austrian Alps (Spötl and Mangini 2002), and from southwestern France (Genty et al. 2003). This non-exhaustive list of results gives a flavor of how speleothem records complement other terrestrial evidence, e.g. from lake sediments (Allen et al. 1999; Brauer et al. 2000) or pollen (Sanchez Goñi et al. 2002; Sanchez Goñi et al. 2008).

In particular, speleothems enable significant advances in providing precise age determination over the penultimate deglaciation (Termination II) and the last interglacial (LIG) period. Could speleothems provide a continuous, well-dated, and wellunderstood reference record for Termination II? We review the speleothem $\delta^{18} \mathrm{O}$ records covering Termination II and the LIG that satisfy the following criteria: (1) They should be characterized by a high density of UraniumThorium (U-Th) ages of high precision (i.e. $2 \sigma$ age error $<1-5 \%$ ), (2) the speleothems should have a high enough growth rate so that samples for U-series dating cover a time interval shorter than the uncertainty of the age, and (3) growth rates should be continuous over long periods avoiding long hiatuses. Following these criteria, we selected seven records from Asia (Fig. 1): four from the Sanbao Cave (China; Wang et al. 2008), two from the Dongge Cave (China; Kelly et al. 2006; Yuan et

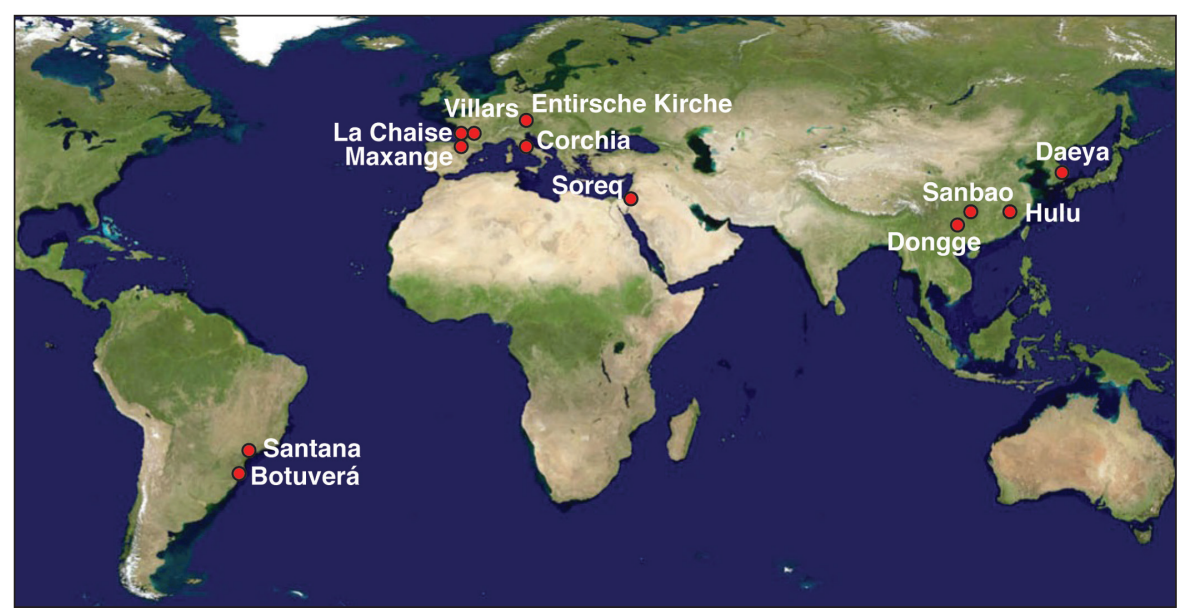

Figure 1: Geographical locations of the selected speleothems.

al. 2004) and one from the Daeya Cave (Korea; Jo et al. 2011). From South America, we selected two records from Brazil. They were retrieved in the Botuvera Cave (Cruz et al. 2005; Cruz et al. 2006b) and in the Santana Cave (Cruz et al. 2006a). We further considered six records from European/Mediterranean caves (Fig. 1) located in Corchia (Italy; Drysdale et al. 2005; Drysdale et al. 2009), La Chaise (France; Couchoud et al. 2009), Entrische Kirche (Austria; Meyer et al. 2008; Meyer et al. 2012), Villars (France; Wainer et al. 2011), Maxange (France; Genty and Wainer unpublished) and Soreq (Israel; Bar-Matthews and Ayalon 2002). While various parameters have been measured on speleothems such as calcite $\delta^{13} \mathrm{C}$ and trace elements, we focus here only on the $\delta^{18} \mathrm{O}$ signal of the calcite and its growth-rate.

\section{Calcite $\delta^{18} \mathrm{O}$}

Several environmental factors influence the sensitivity of the calcite $\delta^{18} \mathrm{O}$ to rainfall $\delta^{18} \mathrm{O}$ and/or temperature (McDermott 2004). Firstly, changes in the location of the water vapor source, in the source's isotopic composition, and also changes in rainfall amount influence the calcite $\delta^{18} \mathrm{O}$. This results in lower $\delta^{18} \mathrm{O}$ when the climate is more humid and warmer, e.g. as shown by monsoon speleothem records and the Corchia record in Italy (Cruz et al. 2006a; Drysdale et al. 2005; Jo et al. 2011; Wang et al. 2008; Fig. 2). Secondly, the temperature in the cave (close to the mean annual external temperature) may also have a significant influence on the calcite precipitation fractionation, and consequently on the calcite $\delta^{18} \mathrm{O}$ (i.e. $\delta^{18} \mathrm{O}$ decreases when temperature increases), as suggested in the Villars stalagmite (e.g. Genty and Wainer unpublished; Wainer et al. 2011). Thirdly, changes in the seasonality of precipitation (e.g. the proportion of winter versus summer precipitation) can influence the calcite $\delta^{18} \mathrm{O}$ in specific cases such as in the Entrische Kirche Cave record (Meyer et al. 2008, 2012) where the seasonality effect drives the increase of calcite $\delta^{18} \mathrm{O}$ over Termination II while the climate continues to warm (Fig. 2A).

\section{Speleothem growth rate}

The speleothem growth rate is also a key parameter for climatic reconstruction. The calcium content of the dripping water and the drip rate mainly control the growth rate. Those two factors are influenced by climatic conditions (e.g. external temperature, precipitation) and soil and vegetation activity (Baker et al. 1998; Dreybrodt 1988). As a consequence, the records from densely U-Th dated speleothems generally reveal a close link between growth rate and calcite $\delta^{18} \mathrm{O}$ (Fig. 2). Within a single stalagmite, the growth rate can vary from a few $\mu \mathrm{m} \mathrm{yr}^{-1}$ during cold and dry periods to more than $1 \mathrm{~mm} \mathrm{yr}^{1}$ during warmer and more humid climate phases. The chronology can, therefore, only be constrained if a high number of precise dates can be generated on an as small as possible time interval.

We observe that all the low-latitude stalagmites from Asia and South America grew continuously over Termination II (Fig. 2B), while in Europe only the Corchia stalagmite seems to present such a progressive growth (i.e. with no hiatus) (Fig. 2A). Unfortunately, the low growth-rate in the Corchia speleothem, less than $30 \mathrm{~mm}$ of calcite deposition from its base at $\sim 170$ until $\sim 129$ ka BP, limits the acquisition of multiple precise ages over Termination II. Chronological limitations also 
exist for Entrische Kirche, Maxange, and La Chaise stalagmites, which started to grow during or just after Termination II and a hiatus is visible in the Villars record before $130 \mathrm{ka} B P$ (Fig. 2A).

\section{Termination II and LIG records}

Figure 2 shows the calcite $\delta^{18} \mathrm{O}$ and growthrate records from the selected speleothems. We observe that (1) most of the European speleothems started growing between 132 and 122 ka BP and all display an abrupt increase in growth rate during a short period: between $\sim 129.7$ and $\sim 125.8$ ka BP (Fig. 2A). On the contrary, the onset of Asian and South-American speleothem deposition and/or growth rate increase is more scattered and ranges from $\sim 138$ to 123.4 ka BP (Fig. 2B). (2) Interestingly, while $\delta^{18} \mathrm{O}$ records show roughly similar changes concentrated around $130 \mathrm{ka}$ in Europe and in Asia, the growth rate changes are much more important in European samples than in low latitude ones (Asia, South America). This suggests that the climatic contrasts between cold and warm phases of the deglaciation are different between mid-latitude and low-latitude regions. (3) The Corchia record, through its comparison with the MD95-0242 marine sediment core (Drysdale et al. 2009), suggests the start of termination II at $141 \mathrm{ka} \pm 2.5 \mathrm{ka}$. This is

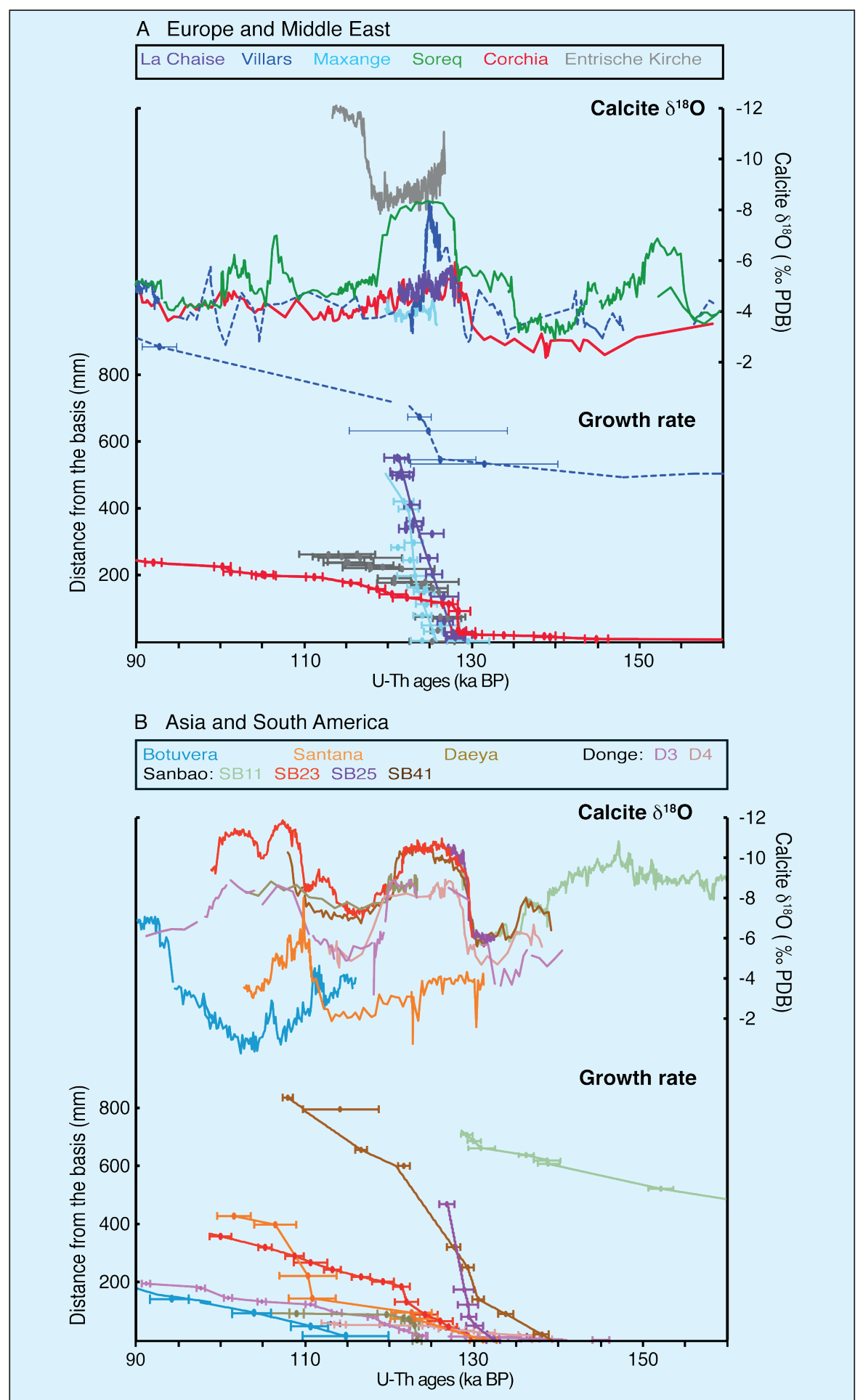

Figure 2: A) Calcite $\delta^{18} \mathrm{O}$ and growth rate records for European speleothems and calcite $\delta^{18} \mathrm{O}$ record for a Middle East speleothem. B) Calcite $\delta^{18} \mathrm{O}$ and growth rate records for Asian and South-American speleothems.

only slightly marked by the calcite $\delta^{18} \mathrm{O}$ and the growth rate curves. No comparable transition signal at this age is found in Asian speleothems, which on the contrary, display a $\delta^{18} \mathrm{O}$ increase interpreted as a weakening of the Asian monsoon. However, a major transition is clearly visible in the Corchia record in both the calcite $\delta^{18} \mathrm{O}$ and growth rate, between $\sim 131.5$ ka and $\sim 128.5 \mathrm{ka}$. Additional well-dated speleothems are urgently needed to shed light on the timing of the onset of Termination II in Europe compared with Asia. (4) A good agreement between the Corchia and La Chaise records is observed for the timing of the LIG climatic optimum and the calcite $\delta^{18} \mathrm{O}(\sim 128$ ka $\mathrm{BP} \pm 1$ ). However, the calcite $\delta^{18} \mathrm{O}$ from Villars Cave, which is geographically closer to La Chaise Cave than the Corchia Cave, reveals a different shape over the LIG and lower calcite $\delta^{18} \mathrm{O}$ values. Interestingly, the Villars calcite $\delta^{18} \mathrm{O}$ amplitude change over Termination ॥ has a similar magnitude to the record from the Soreq cave located in the Middle East.

This comparison clearly reflects (1) different regional responses to climate forcing and (2) region- and site-specific controlling factors of the calcite $\delta^{18} \mathrm{O}$ values.

\section{Concluding remarks}

Speleothem time-series have become an invaluable terrestrial archive to reconstruct climate changes. The $\delta^{18} \mathrm{O}$ records and the growth rate curves discussed here show an abrupt and general warming onset between $\sim 129.7$ and 125.8 ka BP in Europe. Under a monsoon climate regime, we observe also an abrupt variation in the $\delta^{18} \mathrm{O}$ records. However the growth rate curves are much more scattered (i.e. between $\sim 138$ and 123.4 ka BP) suggesting a less marked climatic transition. New data gathered in the framework of the Past4Future project (see Verheyden et al. this issue) should enable us to clarify the observed regional differences over the LIG. In addition, the increasing speleothem demand will certainly need a coordinated and internationally referenced sample management system in order to minimize the impact on cave preservation.

\section{Acknowledgements}

We warmly thank the authors who made their data available to construct the figures.

\section{Selected references}

Full reference listonline under

http://www.pages-igbp.org/products/newsletters/ref2013_1.pdf

Cruz FW etal. (2006a) Earth and Planetary Science Letters 248: 495-507 Drysdale RN etal. (2009) Science 325: 1527-1531 Wainer Ketal. (2011) Quaternary Science Reviews 30: 130-146 Wang YJ etal. (2001) Science 294: 2345-2348 Yuan Detal. (2004) Science 304:575-578 